\title{
Artelogie
}

Recherche sur les arts, le patrimoine et la littérature de l'Amérique latine

$11 \mid 2017$

Délocalités, translocalités et activisme dans l'art électronique et biomédiale latino-américain

\section{Creatividad artificial en los mundos bioinmersivos}

\author{
Iliana Hernández-García
}

\section{(2) OpenEdition}

\section{Journals}

Edición electrónica

URL: http://journals.openedition.org/artelogie/1505

DOI: 10.4000/artelogie. 1505

ISSN: 2115-6395

Editor

Association ESCAL

Referencia electrónica

\|liana Hernández-García, «Creatividad artificial en los mundos bioinmersivos », Artelogie [En línea], 11 | 2017, Publicado el 12 enero 2018, consultado el 19 abril 2019. URL : http:// journals.openedition.org/artelogie/1505; DOI : 10.4000/artelogie.1505

Este documento fue generado automáticamente el 19 abril 2019.

Association ESCAL 


\title{
Creatividad artificial en los mundos bioinmersivos
}

\author{
Iliana Hernández-García
}

Varios resultados y reflexiones de esta investigación se realizaron gracias al apoyo recibido de la Fondation Maison des Sciences de l'Homme, el Institut d'Histoire et Philosophie des Sciences et Techniques de l'Université de Paris I, l'Ecole Normale Supérieure et le CNRS, de Paris, durante mi estadía como Directeur d'Etudes Avancés y como investigadora senior, respectivamente. También gracias al apoyo de la Pontificia Universidad Javeriana en Bogotá, Colombia.

\section{Introducción}

Este artículo es resultado de investigación del proyecto Ecopolitica de los paisajes artificiales realizado por el grupo Estética, nuevas tecnologías y

habitabilidad del departamento de Estética de la Facultad de Arquitectura y Diseño de la Pontificia

Universidad Javeriana en Bogotá.

1 La deslocalización poshumana sigue lógicas no clásicas que se ubican en el horizonte de aquello que es posible, no de aquello que solíamos llamar real, y que signaba finalmente la escogencia y hegemonía de un único valor. La deslocalización del conocimiento adquirido es importante llevarla a cabo para superar como referencia principal la acumulación de acervos históricos e ideologías decimonónicas. Ahora la invitación es a dirigirnos por caminos de innovación conceptual y de una creatividad abierta que deriva en cómo ver el mundo en tanto que posibilidades.

2 Este proceso de deslocalización implica separar la relación de espacio y tiempo que construía la experiencia como garante de verdad, y por tanto implica la independencia del lugar físico/histórico/cultural desde el cual se piensan o asumen los problemas de investigación. Es decir, que la producción de conocimiento para el caso de lo poshumano y las transformaciones ontológicas y epistemológicas de lo artificial, ya no dependen o pueden indagarse desde una especificidad cultural limitada a un sector o región del 
mundo humano, digamos, por ejemplo: Latinoamerica, sino que requiere una visión exoregional, exocultural para adentrarse a un pensamiento exocéntrico, es decir por fuera de lo antropocéntrico, intentando superar los límites de lo humano.

Esta aproximación construye un tipo de camino radical para el proceso creativo, como principio de libertad, y está relacionado con la idea de lo imposible. En los seres semivivos generados y observados en laboratorio y en los trabajos de bioarte sintético, vemos cómo ellos plantean desafíos conceptuales hasta ahora sin precedentes, y producen giros a nuestras comprensiones filosóficas del mundo y en particular a los conceptos de individuo y ser. Con lo cual éstos generan una transformación paralela del concepto de creación como naturaleza y como proceso. ¿Quién crea? ¿Somos los seres quienes lo hacemos? o ¿Es el conjunto de células que somos, dentro del continuum de la vida y la materia? ¿Qué relación existe entre el acto de crear y el de ser? Esta pregunta surge cuando la idea de ser se encuentra en ruptura frente a su relación con otros no humanos que pueden ser maquínicos o de otras especies orgánicas. Esto construye una crisis frente al estado de cosas que desconocemos y frente a la ecología en la cual nos encontrábamos inmersos.

\section{La creatividad artificial como proceso evolutivo}

4 La creatividad proviene no solamente de nosotros como autores, seres, o garantes principales de su emergencia, sino que la creación surge de lo inesperado y lo imprevisible. Es la materia que busca lo imposible, incluso a través de lo conocido. Es el caso de los semi-vivos, donde la vida se busca camino y muestra procesos de fusión entre células de diferentes especies, exhibiendo un comportamiento insospechado dentro de un individuo aislado o en ausencia del cuerpo tecnocientífico.

5 La impredecibilidad es compatible con el determinismo y la emergencia. Lo cual significa que varias posibilidades pueden ocurrir en distintos niveles de emergencia. Es el caso de la fusión celular in vitro de la biología húmeda. Se trataría de cómo es posible que surjan seres híbridos u objetos-animales en el ámbito de la unidad mínima de la célula y en el del enclaustramiento de las especies conocidas desde los inicios del naturalismo y la taxonomía. El filósofo de la biología Huneman dice: "Los sistemas complejos forjan predicciones cualitativas en la base de comparaciones entre simulaciones con múltiples valores y parámetros" (2012: 35). Con lo cual planteamos si la evolución computacional y, en general el proyecto tecnocientífico de la biología húmeda y seca podría producir una emergencia semejante a la esperada por la evolución abierta y sin límite. Se trata de una o varias posibilidades de otra naturaleza o condición. Una con patrones intrínsecos surgiendo a través de procesos computacionales de abajo hacia arriba que consideraríamos inesperados. Empujar los límites de la ciencia puede encontrarse en relación con la creación y la imaginación como novedad. (Casti, 1997)

6 Se puede establecer una relación con el experimento mental de Gould (1989 y 1995), denominado: "Replaying the tape of evolution" (Fontana, Buss, 2011) acerca de cómo la evolución natural y biológica que conocemos podría no haberse producido, pues ella es simplemente una respuesta contingente a las interacciones y las condiciones de respuesta al medio. Se trata de un nuevo comienzo de producción de vida; ahora lo que queda es ver qué ocurre. De forma similar sucede con las obras de bio-arte y telepresencia de Eduardo Kac, tales como Génesis ${ }^{1}$, donde a partir de una traducción de códigos de lenguaje, ADN, 
morse y binario, se opera una intervención in vitro sobre una bacteria en una placa de Petri. Se trata de una combinación entre biología húmeda y bioarte computacional.

7 Estas obras pueden ser interpretadas como información semántica, en un paralelo entre la evolución biológica y los algoritmos genéticos. Se trata de las imposibilidades de la biología evolutiva o por selección natural. Hay una emergencia de novedad en el mundo real, o mejor actual, por cuanto la bacteria literalmente es transformada y los tejidos empiezan a crecer, en el caso de los semi-vivos y ocurre la fusión celular, creando la vida parcial. ¿Qué significa esta transformación actual con relación a las definiciones de vida artificial en curso? En ella existen tres definiciones principales: a. Son entidades vivas, dice Adami (2007), b. Son solo representaciones de un organismo vivo, según Langton (1996), c. Sirven para clarificar hipótesis acerca de lo que sea la vida o cómo se comporta, dice Huneman (2008b).

8 La idea de la evolución abierta y sin límite es el lugar donde podemos encontrar lo imposible, o la vida que no conocemos. Es el puente para una relación entre la vida por selección natural y otras categorías y formas de vida. La teoría explicada por Bedau (2011) acerca de la biología evolutiva recae en la posibilidad que se abre en el sentido de continuación incierta de vida desconocida. Vida artificial y vida natural pueden coexistir, organizando un continuum por rupturas y paisajes de cambio, a través de un comportamiento no determinístico e impredecible. El camino va siendo ocupado por evoluciones en la diversidad. La emergencia y la contingencia devienen robustas y pueden producir novedades a un nivel más alto del esperado.

9 En los mundos bioinmersivos (Hernández, I. 2016, 48) como Tierra de Tom Ray (1991), se trata de una simulación por computador del desarrollo de vida artificial en lo que sería el momento cámbrico de la evolución. Es decir, se intenta producir vida artificial y acaso experimentar cómo se desenvolvió la vida como la conocemos o de otra manera diferente a la existente en la Tierra. Basado en el modelo Darwiniano se construye un lenguaje de código capaz de evolucionar a la manera como lo hace la evolución natural solo que aquí se trata de medios artificiales (informacionales). El código de la máquina puede mutar, recombinarse y así expresar los procesos de selección natural, y no simplemente como una representación. Algunos de estos códigos, los primeros fueron programados por humanos, pero los siguientes corresponden al proceso autónomo de desarrollo de la máquina. El sistema operativo tiene particulares capacidades de memoria y de administración del tiempo. Pueden observarse los nacimientos y muertes de nuevas "especies", secuenciar el código de cada organismo, ver emerger una especie completa, compendiar un banco de genes y obtener ecosistemas artificiales con sus correspondientes procesos de interacción.

10 Se trata de encontrar lo inesperado, de indagar por aquello que se formó y cómo se produjo, o también aquello que puede formarse de otra manera en tanto que vida, pero que no se parece a la que apareció en la tierra. Es la puesta en escena del experimento mental de Gould, acerca de qué sucedería si volviéramos a presenciar el surgimiento de la vida y de la evolución. ¿Surgirían las mismas especies? En el proyecto Tierra se utilizan simulaciones computacionales, pero éstas podrían traducirse en biología húmeda. La simulación se realiza de esta manera para comprimir el tiempo de evolución, pues no podríamos procesarlo en su duración real. También se espera ver cómo ocurre el surgimiento de terceras generaciones de tecnología computacional.

11 Teniendo en cuenta que existen teorías que consideran que la evolución por selección natural ha terminado, ésta sería una idea para continuar la evolución por selección 
artificial. Se trata de cómo avanza la vida biológica a través de procesos tecnológicos, de ir de la bioevolución a la tecnoevolución. Lo cual se relaciona con el concepto de hipercreatividad planteado por Bedau (2004). Será necesario revisar nuevamente la idea de la evolución terminando o ampliándose hacia horizontes múltiples de apertura y ausencia de límites. Y habríamos de hacer una síntesis de los procesos de fusión en relación con la evolución, ahora cultural y por vías de la tecnología.

Es posible intervenir la vida biológica a través de la tecnología. Con lo cual ésta se convierte en vida artificial. En el laboratorio de biología húmeda y sintética organizado por Bedau, McCaskill, Packard, y Rasmussen (2010: 90) se está tratando de producir vida química sintética. Se trata de una Protovida (Protolife) que muestra como posible el crear vida de la no-vida. Se parte de la biología sintética para llegar a la biología húmeda. No se parte de ningún componente vivo conocido, sea éste célula, tejido u órgano, sino de elementos completamente sintéticos. Combinando procesos computacionales y químicos, se va alcanzando distintas etapas de la emergencia de la vida. Es distinto a Tierra, pues en éste, la simulación computacional es la única forma usada para la producción de vida artificial. En los tres casos, se trata de alcanzar la "vida como podría ser", independiente del material del cual esté hecha, y especialmente distinta a aquella que tiene al carbono como base. Cuando esta condición aparece, surge lo inesperado.

La hipótesis sobre la evolución de la complejidad replanteada por Bedau (2006) a partir de los autores que iniciaron su desarrollo tales como Gould (1989) y McShea (1991) entre otros, nos permite pensar en el surgimiento de lo inesperado como parte de la creatividad creciente.

Uno de los más interesantes comportamientos de los sistemas vivos es su creatividad; propuestas acerca de ello se encuentran en Hernández, Niño, Hernández-García (2013). Bedau denomina dicho proceso como hipercreatividad (2004). Lo que hace la vida artificial es sintetizar estos comportamientos y producir otros nuevos a través de simulaciones computacionales. Este camino se focaliza en la creatividad exhibida en los procesos de evolución, en lugar de hacerlo en aquellos de la adaptación o de las particularidades de los organismos y las especies.

Esto significa que algunas criaturas simples pueden evolucionar en otras más complejas, lo cual es la emergencia. $O$ también que ciertas unidades de vida mínima como las células, pueden fusionarse y hacer emerger un tipo de vida como ésta podría ser. Por lo cual pensamos que el concepto de emergencia se relaciona directamente con el concepto de creatividad. Y que esta última ocurre cuando está relacionada con procesos radicales de evolución abierta y disruptiva. La evolución de los sistemas vivos es el proceso de autoorganización más complejo que conocemos. Sostiene Bedau al respecto de la Hipercreatividad, que ésta produce cualitativamente e incluso cuantitativamente más clases de adaptaciones y de diversidad (2004: 216).

En este sentido, las adaptaciones serían creaciones. Su fuerza se encuentra en la diversidad, complejidad y no-linealidad. Se produce un giro en el significado de la creación como intención, hacia algo no buscado, ni esperado. Se trata más bien de una acción colectiva, no intencional pero que emerge con radicalidad. Esta produce saltos cualitativos, los cuales no se encontraban antes y no podían haberse previsto.

17 Se trata de una noción de creatividad no solo en el campo de las artes, sino en todas las actividades, y se convierte en un componente importante para el logro de la vida. Las creaciones biomediales pueden ser vistas como adaptaciones, si estas muestran una 
relación cualitativa y especial con el entorno, no solo el físico sino también el de la mente. La vida artificial produce comprensiones acerca de la creatividad humana, mostrando cómo las cosas podrían ser, y esto lo hace usando el lenguaje de la evolución. Trazamos entonces una relación entre la vida biológica con la vida artificial, y en el intermedio entre ellas nos estamos situando.

Esta clase de doble espacio para lo humano (biológico y artificial) permite distintos tipos de reflexión que llevan a la estimulación de ideas acerca de nuevas invenciones, creaciones, pero también comprensiones sobre la vida como conjunto evolutivo. Con lo cual se amplía a una ecología expandida signada por la creatividad en tanto que proceso.

Nuestra condición de tener una vida a mitad de camino entre la biológica y la artificial y en proceso creciente hacia la segunda, hace que aceleremos el proceso de experimentación en la vida artificial. Esta última, cada vez ocupa una mayor parte de nosotros, no solo como especie, sino también como conjunto de sociedades hechas de sistemas vivos. Nuestra mente y cuerpo nos permiten habitar mundos de vida artificial por haber nacido en una evolución cultural, y de alguna manera no en el centro de la biología evolutiva sino en el borde. Podríamos imaginar que como los virus, las bacterias, las simulaciones computacionales o los semi-vivos in vitro, los humanos somos un caso de borde entre la vida biológica y la vida artificial.

Por lo cual, planteamos relaciones entre la creatividad biológica y la humana, con el propósito de alcanzar la evolución biológica, pues ella nos escapa. Queremos capturarla y comprenderla, y nos preguntamos por su capacidad de producir espontaneidad en sus formas y mutaciones, y cómo lo hace sin recurrir a intencionalidades.

21 Es difícil creer cómo la naturaleza puede exhibir un proceso tan complejo, sin una aproximación teleológica. Pensamos que la creatividad humana, la cual también es artificial en muchos aspectos, podría apropiar esta clase de libertad y autonomía, hacia una riqueza cualitativa. Imaginamos que el proceso de evolución de la vida biológica puede transferirse al proceso de la mente y de la creatividad humana. Cuando la naturaleza evoluciona, exhibe creatividad, por lo tanto, ésta es una cualidad específica de la complejidad. Creemos que la creatividad debe ser algo de especial valor, que amplía hacia nuevas y mayores capacidades.

Entre las razones por las cuales las artes electrónicas y biomediales proponen una relación con la vida artificial, una de las más interesantes ocurre cuando producen una mirada de nosotros dentro de sus procedimientos. Por ello llama la atención el trabajo con cultivo de tejidos y la fusión celular. El arte usa la vida artificial para producir cuestionamientos y sentidos acerca de la evolución y la vida como podrían ser. Emplea procesos simbólicos, experiencias en casos de borde, argumentos críticos, metáforas, analogías. Con ellos aborda lo no predeterminado que emerge de la creatividad como valor intrínseco a la materia. Si lo pensamos desde Prigogine (1997) el concepto de importancia inmerso en la materia es contiguo al de creatividad.

\section{Sistemas creativos complejos}

23 El objetivo es comprender el proceso creativo, a través del trabajo del bioarte y de la vida artificial. Bedau (2004) dice: "La actividad estética es una de las manifestaciones más especiales del potencial creativo de los sistemas vivos" (2004: 217). ¿Cuál es el alcance de dicha afirmación en el sentido del potencial que produce para el arte? Hemos de entrever 
en ello cómo empujar los límites de la creatividad hacia la innovación, a través de encontrar relaciones entre vivir y crear. Hay un camino que conduce de los sistemas vivos complejos hacia los sistemas creativos cada vez más complejos. Podemos ver el proceso creativo en los sistemas cuando observamos la vida como podría ser.

La vida artificial explora cómo puede emerger un orden global a partir de agentes y procesos locales. Un orden abierto e inacabado. Dicho orden coincide justamente con la idea de creatividad. Las artes biomediales y la vida artificial están buscando contingencias en las cuales el proceso creativo pueda mostrar sorpresa y emergencia de sistemas vivos que se adapten en el tiempo. A través de la contradicción de los patrones principales de la vida, puede surgir una ampliación de la producción de sentido. Podríamos preguntarnos cómo acelerar o aumentar cualitativamente dicho proceso, a través de una transferencia de la creatividad biológica a la creatividad humana.

Podemos examinar la idea de acelerar e incrementar dicho proceso, como una situación deseable, y que no sea comprendida como una presión externa. Al contrario, como un proceso cualitativo que forme parte de la disrupción de la no-linealidad. Igualmente, lo que buscamos no es un aumento cuantitativo sino una situación en la cual las ideas creativas puedan sorprendernos por su autonomía e independencia de nuestro conocimiento. Una innovación que continúe siendo no teleológica, no intencional, ni antropocéntrica, paradójicamente incluso, si su intensidad atrae nuestro interés.

Históricamente estamos acostumbrados a ver la innovación y la creación como excepciones. Incluso le damos más valor a éstas cuando aparecen de forma inesperada. Normalmente sospechamos de muchas creaciones cuando se manifiestan en un corto período de tiempo. Pero en esta época estamos viviendo en una situación diferente. Un nuevo valor está mostrando su potencial: la idea de incrementar las novedades, y su utilidad. No solo para producir objetos físicos y eficientes, sino especialmente para la mente. ¿Cómo cambiará el mundo si se habitúa a ver y producir novedades frecuentemente? ¿Podremos detectarlas o diferenciarlas de las que no lo sean? Posiblemente las novedades construirían un paisaje homogéneo que rápidamente quedaría indiferenciado. Y no sabemos si la creación permanecería como un valor, tal como la apreciamos hoy día. Esperamos que lo siga siendo, a través de creer en la capacidad indefinida de la novedad en su semejanza con la vida. Con lo cual los mundos se amplían de una forma cualitativa, escapando a repeticiones, acumulaciones y homogeneidades. La imposibilidad para definir la creación es tan imprecisa como la vida y ésto es una ventaja no intencional. Es un hecho que el concepto de creación evoluciona con cada época, mientras que la definición de la vida también lo hace. Incluso podemos encontrar una correlación entre la creación y la vida en asociación con la tecnología. El proyecto Tierra es un ejemplo de esta idea de evolución y creación relacionadas. Es una máquina de lenguaje que se replica a sí misma, se autoproduce, cambiando incluso sus parámetros iniciales. La vida artificial muestra cómo puede ocurrir dicho fenómeno en el mundo actual, pero también cómo puede ocurrir en cualquier otro mundo posible. A esto lo denominamos la relación entre los mundos bioinmersivos (Hernández, I. 2016: 51) y el concepto de emergencia.

27 La idea de la flecha del tiempo en la complejidad se define a través de la imagen de organismos vivos que tienen una tendencia propia a evolucionar hacia otros más complejos. Pero ello no significa una teleología o alguna idea de progreso. Solo implica que existe tal tipo de diversidad y que cada mundo posible puede manifestarla temporalmente, para luego expresar una transformación tan radical que incluso ya no 
puede leerse como una sucesión del estado anterior o no puede contrastarse con las condiciones iniciales. Las formas de adaptación ya no serán las mismas. En las artes como en la vida de las sociedades observamos esta situación. Se trata de contingencias no explicables a través de procesos lineales o determinados de antemano.

Las contingencias son las formas como la adaptación emerge para responder a las condiciones del entorno. La complejidad sería el grado de libertad y no-linealidad con el cual éstas se manifiestan. A propósito de lo cual Denett agregará que, si volviéramos a hacer correr la evolución como en el experimento mental de Gould, ésta inevitablemente haría aparecer organismos más complejos, inteligentes y con mejores capacidades (referido por Fontana y Buss, 2011:54). Bedau por su parte considera que dicho experimento mental debe llevarse al plano de la biología sintética, creando el sistema en laboratorio y observando cuál es su comportamiento. Se trata de sintetizarlo y observarlo en tiempo actual. El método consiste en medir el poder creativo de la evolución natural. (Bedau et al., 2010: 220) Lo cual se corresponde con el proyecto de Protolife llevado a cabo por él y otros científicos y que hemos citado previamente.

Este coincide con el proyecto Tierra, en el aspecto de poner en marcha el experimento mental de Gould (Beatty, 2011), pero a través de simulación computacional. Se trata de sintetizar la vida sin entrar en biología húmeda. Si nuevas adaptaciones se crean continuamente y la cantidad total de estructura adaptativa sigue creciendo, como fue el caso, entonces queda demostrado el proceso de la evolución en el sentido de la teoría abierta y sin límite y de la complejidad como característica central. (Ray, 1991: 51) Con lo cual, el experimento mental de esta forma de evolución se traduce en la creación de nuevas y mejores clases de adaptaciones, si bien la evolución permanece aleatoria, indeterminada y no teleológica. La creación se convierte en indispensable para la naturaleza y la vida. En este sentido, ella significa disimilaridad, novedad y ausencia de evidencia de lo que puede ocurrir. Es por ello que podemos esperar la emergencia de lo vivo a partir de lo no-vivo, arte a partir del no-arte. Se trata de un evento abierto e inacabado, el cual sigue el camino no condicionado de transformarse a sí mismo radicalmente, muchas veces en su aparente opuesto. Mostrándonos con ello, que las dicotomías son sólo apariencias en la visión limitada del mundo, incluso que la noción de distinción es sólo una explicación acaso temporal de lo que vemos.

Las definiciones en nuestro tiempo se están convirtiendo en algo temporal, y estamos habituándonos a ello, incluso en ciencia y filosofía. No es posible esperar producir una teoría general o un concepto terminado acerca del arte, la creación o la vida. Los fenómenos cambian como contingencias y evidencian el desuso de las definiciones previas. Este fenómeno guarda una fuerte relación con la tecnología y produce un mundo extremadamente cambiante. Asistimos entonces a la aumentación de los procesos a través de la pluralidad de éstos y de las capacidades humanas de percepción y de conocimiento. El proceso cognitivo se ha expandido considerablemente.

31 Por lo tanto, las experiencias prácticas que podemos realizar al intervenir la vida o al producirla, constituyen el cambio más importante. ¿Qué significa en términos de creatividad el que podamos intervenir la vida incluyéndonos a nosotros mismos?

Esta es la hipercreatividad a la cual se refiere Bedau (2004) y la vemos en la biosfera y en la vida artificial. Los sistemas complejos están mostrando esta clase de creatividad en la evolución de la vida. En ella se encuentra lo imposible, para estimular hacia un comportamiento más complejo, el cual permite la emergencia de nuevas adaptaciones. 

permitan nuevas adaptaciones cualitativas, tales como la vida multicelular, la vida en la tierra u otros cambios significativos." (2011: 59) La vida en la tierra emergió sorprendentemente cuando nada de lo que ocurría podría haber supuesto que ello sería posible. Análogamente el surgimiento de la vida química sintética correspondería con esa adaptación radical posible, que parece imposible a partir de los procesos conocidos y que han limitado los parámetros de lo que sea la vida. Por lo cual se habìan reducido las posibilidades de experimentación o de emergencia de novedad, pues todo se confrontaba con lo conocido.

Denett (1982) al respecto argumenta que:

"La teoría de la inteligencia y el proceso creativo puede explicarse como una cascada de algoritmos generativos. El proceso de la selección espontánea crea organismos bien adaptados. El ejemplo de los "memes" de Richard Dawkins, significando las ideas, proyectos y conceptos que la cultura produce, ilustra esta idea. Las innovaciones meméticas pueden aparecer en cualquier momento y pueden incrementarse o decrecer. Pero si las colocamos todas en una especie de piscina memética, imbuidas en un proceso de selección artificial, éstas pueden interactuar entre ellas, haciendo que las innovaciones ocurran de forma acelerada y que se incrementen." (1982: 39)

La piscina de memes fue Internet inicialmente, pero ahora consiste en el conjunto de simulaciones computacionales bioinspiradas conectadas entre sí y el conjunto de tejidos vivos y fusión celular vinculados a través del cuerpo extendido (Catts y Zurr, 2006) o del cibionte (Rosnay, 1995). Estos conjuntos conforman paisajes de sistemas sociales y artificiales. En ellos, las ideas y los conceptos han sido construidos de forma sintética e interactúan entre sí, en un estado indeterminado entre imagen y objeto, estructura colectiva y organismo. Están juntos, el uno al otro como nunca lo habían estado y probablemente por esta razón, antes de 1995 no habíamos visto un aumento de novedades cualitativas. La ciencia producida a través de la web y en acceso abierto ha sido otro de los ejemplos de piscina memética que incrementaron las innovaciones, pero éste no fue su propósito. La pregunta acerca de cómo puede producirse nuevo conocimiento sigue pendiente y está al centro de la creatividad.

\section{Creatividad creciente}

La manera particular cómo se desenvuelve la evolución a través del juego de posibles y de la no-linealidad describe un proceso abierto e indeterminado. La habilidad de crear diferentes formas y más complejas que otras, es el reto para explicar la emergencia de una hipercreatividad que incluye también a los humanos, pero que no se limita a ellos. La evolución natural o artificial implica ella misma la creatividad, la cual al presentar un tamaño y alcance tan amplio cuantitativa y cualitativamente es denominada con el prefijo hiper. Esto hace relación al hecho que la creatividad se extiende en el espacio y en el tiempo a través de múltiples dimensiones y participantes, aunque no existen todavía, pero pueden aparecer. Es un proceso que crea y a la vez que es creado. Autónomo y a la vez aleatorio. Sin autores ni planeamientos. Solo deviene sin una visión teleológica y su capacidad de producción de diversidad no es medible aún. La hipercreatividad tiene que ver con la vida artificial. De cómo ésta amplía, acelera, comprime en el tiempo y el espacio la aparición de novedades en la evolución, tal como en la piscina de memes. Esta actividad se relaciona con la hipercreatividad humana. No por su dependencia de los humanos, sino 
por la relación que lo artificial establece con nosotros, tanto en su origen, como en su inicio y puesta en marcha. La evolución natural es creativa, la evolución artificial (que incluye la natural) está siendo hipercreativa. Y ella está transformando ahora el mundo humano, lo está aumentando en sus capacidades y alcances, así como la evolución lo ha hecho con los seres vivos.

Las nuevas posibilidades emergen donde no había ninguna evidencia de que ellas podrían emerger. Ese es el significado de los mundos posibles en relación con la innovación que ellos contienen o que se pueden gestar allí. Los mundos posibles son un conjunto de sistemas produciendo novedades continuamente, una especie de piscina memética, donde las emergencias entran en relación entre ellas y aceleran el surgimiento de otras nuevas. Asi, hemos explicado que el objetivo no es la creatividad normal y de la vida de todos los días, o aquella de escalas de espacio/tiempo humanas, sino una creatividad creciente, la cual como prueba desborda la actividad de nuestra mente.

Por lo tanto, el modelo mimético de creatividad no es el objetivo, sino un modelo que desafíe una creatividad más alta y compleja. Al respecto Bedau (2011) plantea:

“CCómo producir nuevas clases cualitativas de creaciones? El mecanismo es análogo a lo que hace falta en los modelos de creatividad biológica. El camino más constructivo para producir y evaluar una buena explicación, consiste en construir en computador un sistema que sintetice esta hipercreatividad" (2011: 68).

Nuestro objetivo es comparar y acercar los trabajos de bioarte, con este enfoque, en el sentido de examinar de qué manera éste arroja luces acerca de la hipercreatividad, en tanto que sistema que produce vida de la no-vida. Seguramente serán aspectos específicos o imágenes conceptuales que trazan mundos posibles para ese conjunto mayor. La creatividad experimenta procesos de aumentación con cada innovación que se genera en la cultura. Una aceleración de dicho proceso podría sobrevenir con la aparición de un modelo que emerja a través de conseguir una innovación radical en la comprensión de cómo funciona ésta en la evolución. El proceso de cómo ésta se produce solo se conoce parcialmente, por ello las definiciones de vida están transformándose y esperando por una nueva. Pero sólo podrá lograrlo aquella que al producir vida de la no-vida, en realidad encuentre aquello que hace falta a la descripción de un modelo acertado. Un modelo de cómo crear vida es comparable con un modelo de evolución y con un modelo de creatividad.

El proyecto Protolife de Bedau, Rasmussen et al. (2010) propone temporalmente un modelo que está siendo probado en laboratorio. Este se denomina CPM, y consiste en tres características indispensables para la producción de vida minima: Contención, Programación y Metabolismo. (CPM es la sigla construida con las iniciales de las tres características). La contención hace relación a cómo la vida se mantiene, no desaparece, se hace robusta. La programación hace relación a los procesos que intervienen en la evolución y avance de sus características y que por la denominación está ligada a lo artificial como capacidad exacerbada de los procesos naturales, ahora aumentados por la tecnología. Y el metabolismo se refiere al procesamiento de recursos del ambiente y del entorno. Es decir, se trata de recursos de energía, alimentación y memoria.

41 Este planteamiento de gran interés para la vida artificial, la biología sintética y muchas otras áreas, lo es para la producción de una teoría abierta sobre cómo emerge el conocimiento nuevo a través de procesos creativos. En un futuro podremos crear tecnología con todo el poder creativo de los sistemas vivos. Habría una comprensión y 
transferencia del proceso de creación de lo vivo hacia diversas áreas. Lo vivo operaría como una cualidad, no una esencia aislada o desconocida. Se independizaría el concepto de lo vivo del de ser.

La creatividad en los humanos puede ser aumentada a través de la tecnología y especialmente por medio de interfaces. Los mundos bioinmersivos son grandes interfaces que envuelven nuestros sentidos y procesos cognitivos para propiciar una interacción en un conjunto de posibilidades. Pero ese no es su único propósito. Desde el momento en que estos mundos se relacionaron con la vida artificial aumentaron su alcance en la creatividad creciente. Se trata de colocar a prueba las teorías de la biología sintética, hasta observar qué nuevas formas de evolución surgen en estos universos de interacción, multiplicación y crecimiento de vida. Una vida como podría ser, más allá de la vida conocida y que se despliega por cooperación y reproducción. Estas interfaces continúan evolucionando y plantean modos de conexión con proyectos como Tierra. En este tipo de búsquedas, ellos producen opciones, aumentan y aceleran las posibilidades de la evolución creativa artificial.

Si el mundo como lo conocemos ha sido cambiado por los humanos, podemos suponer que nuestra influencia e interacción haya sido un factor importante. Siendo esto un hecho, podemos esperar que la complejidad venga en aumento. Asi como imaginar que los mundos inmersivos no solo son una sala en una galería o en una red en Internet, sino que participan de un conjunto de sistemas interconectados y en proceso de interacción entre ellos mismos. De forma similar en el proyecto Protolife, si el modelo de CPM se prueba como preciso, ésto permitiría vincular los modelos de vida artificial con los procesos creativos y cognitivos humanos. Así, alcanzaríamos la creatividad creciente en los modelos y en los mundos posibles humanos o no.

En cuanto a la vida química mínima, Bedau (2011) propone que: "No hay un consenso sobre lo que sea la vida, pero parece que podemos distinguir entre lo que está vivo y lo que no lo está. Pero ¿cómo podemos hacerlo? ¿Por qué un pájaro está vivo y un río no?” (2011: 59). En los mundos de bioarte inmersivo, existen trabajos que buscan presentar el río como vivo, el Amazonas. El artista brasilero José Wagner García tiene una conocida propuesta al respecto, titulada Amazing Amazon: 0 rio pensante (1992). A lo cual este autor agrega: “¿De qué manera precisa se diferencia la vida de la no-vida? Dado que las cosas vivas están compuestas por las no-vivas, por lo tanto, la vida es un proceso emergente a partir de lo simple." (2011: 60). La distinción es solo escalar, es decir un problema de grados. Sostiene el autor: "¿Cómo podemos decir si una molécula producida en laboratorio alcanza las condiciones de estar viva, si no tenemos una definición?" (2011: 60). Pero no tendremos una definición hasta que se lleve a cabo el proceso en laboratorio, y hasta que el proyecto de Protolife (o alguno similar) produzca la síntesis de la vida.

Estamos interesados en conocer cómo se relacionaría la emergencia de lo imposible con la aparición de la vida sintética. Esto con el objetivo de conocer cómo establecer un vínculo entre las creaciones diarias y aquellas radicales, y así entender cómo se diferencian. Así mismo para ampliar la comprensión sobre las innovaciones más robustas y estar preparados cognitivamente para experimentarlas. Con relación a ello el autor explica que: "Los materiales químicos son abstractos, y solo se concentran en las funcionalidades químicas. Cualquier realización material que mantenga las funcionalidades químicas será vida mínima. Para producir vida de la no-vida en laboratorio, y luego demostrar una definición de la vida basada en CPM, como las principales funcionalidades. CPM:

Container-Metabolism-Program." (2011: 61) 

vida, solo desde materiales normalmente considerados "inertes". Es una apuesta radical que permite simplificar la comprensión y partir de elementos básicos como los materiales, ignorando su importancia para el resultado y concentrándose solo en la función. Es interesante, porque muestra cómo ampliar la creatividad a través del vínculo inédito entre elementos conocidos, pero no relacionados con dicha función: la de la vida. Es lo que llamaríamos un arte de los componentes.

trata de un camino analítico para establecer un resultado específico o incluso programado, que puede alcanzarse a través de la reducción. Se trata de una emergencia creativa de algo que puede surgir o no en relación con el proceso cualitativo y a la vez abstracto. Recordamos a Ilya Prigogine (1997) cuando manifestaba que la creatividad es un proceso. Específicamente uno radical. Se trata de un hiperproceso que requiere decisiones decoherentes, como ignorar lo que usualmente formaba parte del proceso. Por analogía, podríamos decir que la creatividad podemos sintetizarla en computador para intentar comprenderla o tener una definición. Podríamos separar la creatividad del dominio de los humanos, ignorando lo que siempre se ha creído. No tener en cuenta que ésta ha sido una de sus características distintivas, incluso exclusivas. El objetivo es utilizar el proceso como espejo de lo que queremos comprender, y verlo en otro contexto, más abstracto y desprovisto de las circunstancias que normalmente signan de manera predeterminada su explicación.

Ya trabajamos creativamente en computadores y estos han mostrado procesos con dicha característica de forma a simular nítidamente la producción artística, tanto en el plano cuantitativo como cualitativo. Lo que no hemos alcanzado es un modelo de una creatividad más radical, que incluso supere lo que normalmente consideraríamos. Se hace necesario un proceso separado del arte, o considerar éste como una forma de creatividad que cambia con el tiempo y el contexto, y no como una forma esencial. Se trataría de sintetizar el arte como una producción simbiótica entre el ser humano y la hipercomputación, de naturaleza estética y en permanente aumentación cualitativa de sus grados de creatividad. Por lo tanto, la estética de lo posible, a través de lo imposible, sería la teoría para aumentar la creatividad, mediante la vida artificial húmeda y computacional, la biología sintética y la teoría de la evolución abierta e inacabada.

Langton plantea que: "Las simulaciones computacionales son genuinas formas de vida" (citado por Bedau, 2011: 68). De esta forma queda resuelta la aumentación de la vida, a través de la inclusión de otras nuevas manifestaciones. Se reconocen en otros materiales distintos al carbón. La diferencia entre la simulación computacional que plantea Langton, y la que hace el proyecto de ProtoLife, es que éste último es un sistema de química húmeda, no solo un programa. Con lo cual considera que su resultado no será una representación o una metáfora de la vida, en ningún sentido, sino directamente la vida misma. Su propósito es doble: producir vida de la no-vida, rompiendo los fuertes paradigmas de las distinciones y las dicotomías, y luego obtener el proceso que demuestre la emergencia y describa un modelo para una definición general de vida. No solo de la vida como la conocemos, sino de la vida como podría ser. Afirma el autor que: "La vida en otros planetas puede no tener ADN, proteínas o agua líquida. Esto significa que las funciones CPM pueden operar sin ADN o ARN" (Bedau, 2001: 67).

El modelo CPM es de evolución abierta e inacabada o sin límite, dado que éste explica las operacionalidades de manera funcional. Existe una evolución conceptual de la definición 
de la vida. Lo que interesa no es el significado de la palabra vida, tampoco las habituales concepciones de ésta, sino la presencia y definición del fenómeno tal como éste aparezca. Una nueva idea de vida surgirá sin duda con este procedimiento, y se hará parte de la evolución conceptual que tendremos de la vida. Se espera que esta definición pueda explicar la mayoría de formas posibles de vida que puedan existir en el universo. Con lo cual este proyecto es uno de los más radicales e interesantes, pues no se circunscribe a la vida en la tierra y está incluyendo la vida como podría ser, incluso sin que ésta haya ocurrido aún. La vida entendida como un proceso de creación, si bien emergente, sorprendente, inexplicable aparentemente, podría eventualmente escribirse a través de la forma particular de interacción entre materiales. El alcance es establecer la vida mínima química.

Bedau argumenta que: “...se trata de plantear una teoría de la vida que explique los casos de borde y los rompecabezas de la vida, dado que en ellos están los fenómenos fundamentales de ésta. Pues si bien no hay consenso sobre lo que sea la vida, sí hay acuerdo acerca de algunos casos que comparten elementos, características y problemas en estado límite hacia alcanzar o no el calificativo de vivo" (2011: 77). Por tanto, en ellos se considera que está la clave para alcanzar la vida mínima. Estos casos siempre aparecen en las discusiones sobre lo que sea la vida y lo que no. Además, ellos refuerzan la posibilidad de que la evolución sea abierta y sin límite. Sostiene el autor que:

"Los rompecabezas y casos de borde de la vida explicarían si la distinción entre la vida y la no vida es dicotómica o continua. ¿Por qué la vida es jerárquica, y por qué las cosas en diferentes niveles están vivas? ¿La esencia de la vida envuelve la materia, la forma y otros elementos que no conocemos? ¿Cómo están relacionadas de manera fundamental la vida y la mente? ¿Por qué es tan difícil la respuesta a qué sea la vida? La vida química mínima es cuestión de grados" (2011: 78).

Esta es una idea importante, porque romperá no solo la dicotomía, sino también la idea de la vida misma. Pues si la vida es cuestión de grados, tal vez implique que puede ser producida, alcanzada a través de medios conocidos como la computación y el trabajo en laboratorios de vida química. De igual manera puede ser transformada desde el inicio. Es interesante observar que el misterio acerca de la vida es una de las bases de la cultura humana y que desentrañar la clave, podría modificar de manera radical la visión ontológica de lo denominado humano. Una diversidad de aproximaciones sería generada para producir vida como parte de un proceso tecnológico y de sentido. Los límites de lo posible realmente quedarían modificados no solo de forma pragmática, sino en la construcción de la mente. ¿Estaremos experimentando la naturalización de la mente? ¿También su materialización? ¿Cuáles son las implicaciones de la naturalización del humano? ¿Cómo se transformarían las estructuras del conocimiento siendo que la mayoría están basadas en la tradición?

\section{Tecnologías vivas y mundos bioinmersivos}

Bedau et. al. (2010: 89) describen la tecnología, a través de pensar en la evolución de ésta como un sistema vivo, como la continuidad de la evolución biológica en la tecnoevolución y como parte de la cultura. Estas ideas comenzaron en el 2001 en el Congreso en Nuevo Méjico en el Instituto Santa Fe, fueron producidas por un trabajo de cooperación entre las instituciones siguientes: European Center for Living Technology (ECLT) (Venecia, 2004), Center for Fundamental Living Technology (FLinT) (Odense, Denmark, 2007), ProtoLife 
(Venecia, 2004), European Comissions, Los Alamos National Laboratory (desde el 2004), y finalmente: Initiative for Science, Society and Policy ISSP (2010) destinada esta última a políticas sociales de largo alcance.

Se trata de una tecnología que está basada en la vida mínima. Organizan tres tipos de tecnología viva: la húmeda (wet life hecha en wet laboratory), hard (robótica) y soft (software), refiriéndose a la vida artificial. La noción de tecnología viva produce un giro frente a la idea de vida tecnológica que colocaba en crisis a la ontología clásica. Bedau et al. (2010) enfatizan que la diferencia entre tecnología y vida hace difícil definir la tecnología viva y esto coincide con el aspecto epistemológico que deseamos desarrollar. Afirman que: "Una parte de la tecnología existente ya está viva. Esta es capaz de ser robusta, autónoma, puede repararse a sí misma, autoproducirse, evolucionar, adaptarse y aprender" (2010: 91). Otras nuevas tecnologías vivas continúan surgiendo y con características distintas, además de las explicadas aquí. Para estos autores, la tecnología viva y la vida mínima química están relacionadas dentro de la misma proposición. La diferencia sería que la tecnología viva puede considerarse como una forma de vida y la vida química es un alcance de la primera, y se dirige a definir las condiciones mínimas necesarias para que haya vida. Pero ambas buscan una definición general, incluyente, y caracterizan la manera como nos estamos acercando a ella, es decir, claramente a través de la tecnología. Lo cual incluye no hacer distinciones entre natural y artificial o entre humano y máquina.

Estas son razones interesantes para focalizarse en la tecnología viva, y encontrar en ello un desafío epistemológico. Esto podría cambiar nuestras concepciones habituales. Podríamos encontrar vínculos con las creaciones artificiales, a través de la construcción de un puente entre la producción de tecnologías vivas y las creaciones.

A partir de lo anterior podemos imaginar si la relación entre humanos y los modelos de vida artificial pueden incrementar la evolución. Una proposición que se puede experimentar en los mundos inmersivos del bioarte.

Estos mundos pueden actuar como un entorno para corporeizar propiedades de la vida, tales como autonomía, autoreproducción, evolución, adaptación y aprendizaje, pero especialmente aquellas inesperadas y que encontramos como novedades. Es decir, no sólo de organismos se trata, sino de la emergencia de nuevos rasgos de la vida en su propio proceso. De esta forma, consideramos que la propiedad de la emergencia estaría al centro de los mundos bioinmersivos y ella surge en relación con la interacción entre los agentes y los humanos participando. Quien explora esta idea de manera precisa es el artista Jon McCormack $^{2}$ de la Universidad de Monash en Australia.

Entre las tecnologías bioinspiradas y las biomiméticas, podemos encontrar esta idea. "El comportamiento flexible y adaptable de un robot no está determinado por un control centralizado. El actúa de manera similar al comportamiento de un insecto". (Clark, A. 1998: 34). Esto es importante para nuestro propósito, porque define el tipo de interacción que podemos tener dentro de un mundo inmersivo. Es una interacción no centralizada, pero definida por varios sistemas que reaccionan de forma no jerarquizada o planeada. Permiten la espontaneidad y la producción de resultados que no se esperaban al principio de la simulación. La interacción sería algo como una aproximación cognitiva en el mundo actual. Esta clase de diversidad y emergencia del comportamiento humano puede sintetizarse en robots por la vía del actuar abierto y no lineal. Su entendimiento es un 
recurso importante para el proceso creativo que puede enriquecer los modelos de vida artificial de los mundos bioinmersivos.

Bedau et al. (2010) dicen que: "La diferencia particular entre la primera tecnología bioinspirada y la actual, es que ahora estamos alcanzando la transformación de materiales no vivos con tecnología que se vuelve viva ella misma por sus propios medios. Es decir: tecnología viva primaria y no secundaria". (2010: 95). Se trata de sistemas tecnológicos volviéndose vivos. La tecnología primaria sería aquella surgiendo de materiales y componentes que nunca antes estuvieron vivos, por lo tanto, es completamente artificial. Un ejemplo de ello son los materiales artificiales que se autoproducen como vivos, por ejemplo, las protocélulas. Este trabajo ha sido realizado por el proyecto ProtoLife. Y la tecnología viva secundaria es aquella definida por Bedau et al. (2010) de la siguiente manera:

"Ella depende de antecedentes con propiedades vivas en sus componentes. Otros ejemplos serían la reingeniería de la bacteria E. Coli para generar productos farmacéuticos, o la biología sintética basada en el sistema de traslación de proteinas, o incluso la red World Wide Web. Las comunidades sociales en las redes podrían ser un caso de borde entre tecnología primaria y secundaria." (2010: 96).

Encontramos que uno de los propósitos de la tecnología primaria es que sería la forma más simple de vida y puede definirse operacionalmente y ser usada para probar hipótesis empíricamente. Puede descubrir si un material tenía o no vida previamente, y combinarlo con otros componentes y hacer emerger vida en él. O clarificar los componentes vivos y no vivos, al interior de un conjunto vivo.

61 Si bien la transición emergente hacia la tecnología viva es la vida artificial y las nano-bioinfo-cogno tecnologías y ciencias (NBICS), la tecnología viva se focaliza en construcciones alternas de la vida, (teórica y concreta) con el objetivo de comprenderla más allá del nivel de su aplicación. La biología sintética contiene dos tipos de tecnologías vivas: la que responde al modelo top-down, el cual modifica los sistemas y tiene gran uso en biología e ingeniería genética. Y la que opera con el modelo bottom-up, con lo cual produce nuevas formas de vida en el laboratorio a partir de materiales no vivos. Es el caso del procedimiento con protocélulas, donde no se explotan materiales previamente vivos.

Es necesario distinguir la tecnología pre-viva de aquella que es biomimética. La primera es más interesante y se corresponde con la tecnología viva primaria. Es artificial en el sentido en que proviene de una intención humana, pero es natural en el sentido en que crece, se adapta y evoluciona autónomamente y tiene vida propia.

Existen varias instituciones trabajando en el tema de definir y actuar en responsabilidades sociales científicas. El proyecto ProtoLife directamente tiene un frente de propuesta y acción al respecto. Se ha construido una relación entre los aspectos éticos de la tecnología viva y el sentido de construirla. Se trata de una relación entre la importancia de producir innovación y la expansión de los límites de la vida y cómo éstos pueden ir moviéndose de manera adecuada. Una racionalidad que define el corrimiento de fronteras de la vida, de manera informada y consciente. Se trata de hacer responsable a la sociedad también, acerca de la importancia de la apertura del conocimiento y de la tecnología viva. La construcción de los protocolos adecuados, los procedimientos y los acuerdos acerca de los aspectos éticos ha sido también responsabilidad y trabajo de las instituciones de investigación y de los laboratorios que las producen. De manera que su contenido es informado y la ética actúa no como horizonte de límite sino de posibilidad 
racional. La ética hace entonces un giro para encontrarse con nueva investigación acerca de lo vivo, y trata de proponer una formulación que permita la continuidad del proceso de investigación.

Abordaremos a continuación los mundos bioinmersivos como propuestas conceptuales y sensibles en torno a lo vivo, la imagen y la tecnología (Hernández, 2010). Estos mundos se definen por su característica de inmersión física/tecnológica, conceptual y sensible, en un dispositivo capaz de articular un mundo posible a través de un sistema de interconexión entre dominios distintos de seres vivos: orgánicos o artificiales.

El trabajo del artista colombiano Juan M. Castro, llamado Heliotropika, y presentado en 2011, en la exposición The Visceral, organizada por el grupo Symbiotica en Dublin, es una instalación interactiva biomedial, en la cual se generan conexiones a distintos niveles y entre agentes de naturalezas en principio sensiblemente distintas. Estos son microorganismos, humanos y energía. El proyecto se focaliza en las cianobacterias como tema principal, por cuanto ellas simbolizan el surgimiento de la vida, en cuanto a que gracias a ellas se produjo el oxígeno con el cual la mayoría de seres vivos respiramos y existimos. Prácticamente ellas constituyen un caso de borde de la vida. El interactor es invitado a entrar al entorno y a través de una interface interactuar con este conjunto de cianobacterias, integrándose a la actividad fotosintética que se está realizando allí, a partir de una luz dinámica que se desplaza en el espacio. Los participantes todos, tanto los visitantes como las cianobacterias y la luz producen una actividad bioeléctrica, que es aquella que los une en un proceso de conexión de sus morfologías en principio tan diferentes, pero reunidas aquí por la energía que emite lo vivo.

El texto de la exposición lo describe así:

"Usando cultivo de células y visión computacional, este trabajo ofrece la actividad fotosintética de las cianobacterias en la forma de una estructura orgánica. También produce geometrías dinámicas de energía solar a través de analizar información ambiental. Simultáneamente, este trabajo transforma la actividad del sistema nervioso de cada participante, en "luz" para estimular las células. Como resultado, los visitantes y las cianobacterias se influencian entre si, dando subsistencia a un sistema dinámico de retroalimentación. Este conjunto, ofrece la posibilidad de interacción entre distintos dominios, organizando un sistema que puede proveer reflexiones e ideas acerca de patrones que dan cuenta de la coexistencia de la vida." (www.symbiotica.uwa.edu.au)

En este trabajo encontramos que la vida orgánica está coexistiendo entre especies y dominios, si bien los organismos provienen de diferentes escalas y características. Se muestra en ello la traslación de las propiedades de lo vivo, en información que permite la intercomunicación entre los dominios diferentes, el de las cianobacterias y el de los humanos principalmente. Esta comunicación se da en un proceso cognitivo al cual los humanos no estamos acostumbrados o no tenemos conciencia de ello. Es decir, las bacterias y los humanos estamos estrechamente relacionados, inseparablemente, pero en entornos normalmente no disponibles para la observación humana, por la pequeña escala, que no permite verlas a simple vista, o por encontrarse en entornos cerrados. Sin embargo, también sabemos de las bacterias que están presentes en nuestra vida de forma cotidiana; algunas son indispensables por ejemplo para el metabolismo digestivo, y otras nos resultan negativas como las que producen infecciones. Pero en general, estas actividades no han producido un aspecto cognitivo y estético evolutivo. Ellas producen un mundo en el que nos damos cuenta de su existencia a niveles de la sensibilidad y la abstracción que genera la luz y su dinámica de vida. Así como notamos su relación con 
nosotros a través de la tecnología como interface o máquina de visión. De otra parte, vemos cómo nuestro sistema nervioso puede ser también traducido para la bacteria, en una forma que produce también "actividad" para ella. Por supuesto, el contexto de significación tiene dimensiones humanas en la parte que sabemos de él, ignoramos qué sensación produzca al conjunto de bacterias. Sin embargo, continúa siendo un contexto de entendimiento para nosotros. Nuestras características vivas tales como las cognitivas, expresadas por el cerebro y el sistema nervioso, pueden tener una expresión aquí, en el nivel de la conectividad con otras formas de vida orgánica. Y eso es algo de lo cual no estamos conscientes normalmente. Este se convierte en un mundo que ofrece una forma de interacción y que contribuye a aumentar la creatividad en un sistema orgánico/ artificial, haciendo una traducción escalar y de elementos (incluida la luz), los cuales manifiestan la vida de las bacterias, a un nivel sensible compatible con nuestra percepción.

En el trabajo Edén del artista Jon McCormack. (http://jonmccormack.info/ jonmc/sa/) se trata de un mundo capaz de producirse y transformarse a sí mismo a través de su propia evolución. Una relación de abajo hacia arriba (bottom-up) entre criaturas que se cruzan y un entorno que genera una termodinámica de la vida. El sistema se auto-organiza permanentemente de forma a generar innovación. Presenta un conjunto de rasgos de comportamiento y de maneras de existir, las cuales aparecen inesperadamente. Se expresa los conceptos de emergencia y de adaptación en la manera como las criaturas aprenden a desenvolverse en el ambiente de la instalación, incluso pasando el conocimiento adquirido a sus crías.

Siendo un sistema interactivo, la obra se completa como mundo bioinmersivo, pues éste implica el nivel de relación sinérgica entre visitantes y el entorno virtual. Como mundo, está organizado a través de unos patrones particulares de funcionamiento, los cuales definen ciertas posbilidades de evolución a partir de existencia de materia y producción de sonidos de unas características especiales para producir interés. Sin embargo, es un mundo abierto e indeterminado, pues nuevos patrones surgen, independientes de aquellos determinados al comienzo. Y estos rasgos de evolución dependen del tipo de interacción que se produzca con la audiencia, el cual claramente, es imposible de predecir. Igualmente en el sistema, no se diseñan todos los patrones de comportamiento, algunos se dejan abiertos, esperando su transformación a través de la manera como las criaturas se adapten entre ellas y con el entorno, y luego con los visitantes. En ambas situaciones no hay predicción o plan preconcebido. El mundo es bioinmersivo porque nos ofrece un espacio/tiempo indeterminado que no puede ser anticipado de antemano, y cuya evolución radical signa posibilidades de innovación, antes inesperada en los mundos inmersivos habitados. Es en este sentido que consideramos una relación entre la evolución y la creatividad. Por cuanto la forma como estos mundos evolucionan, implica no solamente una transformación en una dinámica específica, sino la emergencia de algo nuevo, en un ecosistema artificial. Esta novedad se manfiesta en las diversas maneras de existir que empieza a mostrar el sistema, y que se diferencian de las criaturas iniciales. Una emergencia que no podía haberse deducido de las condiciones iniciales. Y una creación que no tiene autor, pues surgió sin un plan o diseño, sin una intencionalidad que definiera cómo debía ocurrir. En este sentido hablamos de una innovación creativa, por cuanto supera las condiciones de la creatividad habitual, al punto de representar la idea de creatividad creciente.

En otra obra de Jon McCormack, denominada Flicker, encontramos: 
"Flicker es un entorno electrónico inmersivo compuesto de imagen y sonido generativo. Es un trabajo colaborativo realizado con Oliver Bown. Está basado en modelos biológicos del comportamiento de la luciérnaga. Flicker genera un ritmo infinito de luz encendiéndose y apagándose, el cual se convierte en un entorno meditativo para el visitante. Flicker usa cuatro canales de video sincronizado de alta definición y ocho canales de sonido, para producir la sensación de inmersión en el observador, y sumergirlo en un entorno fenomenológico variado de vida artificial. El trabajo consiste en una simulación computacional de gran escala, basada en agentes, donde cada agente provee un pulso rítmico de intervalos regulares. Los agentes tratan de sincronizar su pulso con otros agentes en el vecindario inmediato. Las pulsaciones colectivas de los grupos de agentes locales, son convertidas en sonido espacial en el entorno de la exhibición. Con el paso del tiempo, algunos grandes grupos se sincronizan a ciertas velocidades, dando lugar a estructuras visuales y aurales complejas. Se sincronizan en un constante tintilleo, dentro de una complejidad de largo alcance." (http://jonmccormack.info/ jonmc/sa/)

71 Este trabajo literalmente vincula los modelos bioinspirados basados en agentes, con los modelos de mundos inmersivos. Nos aporta de manera singular en el propósito de crear una teoría que relacione estas dos aproximaciones y modelos. Lo que es interesante consiste en la producción de una inmersión en un mundo posible hecho de rasgos de vida. Es un modelo artificial de una simulación inmersiva. Genera una sensación kinestésica, meditativa, convocando nuestros sentidos y nuestra cognición, para construir un mundo posible inspirado en los paisajes rugosos adaptativos de la evolución de la vida. El reto que nos proponen ambos trabajos de McCormack, es mantenernos en el plano de la abstracción, tanto visual como sonora, sin pasar al plano figurativo o metafórico, como ocurre con otras simulaciones bioinspiradas. No existen caracterizaciones de los organismos, solo la situación inmersiva abstracta de una evolución abierta de la vida que hace emerger algunos patrones inesperados. Se trata de un paisaje matemático singular, que expresa en el sonido y en la intermitencia visual un ámbito de lo sensible y de lo inteligible. Estos ámbitos se conjugan para explorar las posibilidades de la creatividad en la evolución.

\section{Conclusión}

Al buscar lo imposible, lo encontramos en aquello que hace falta para producir un modelo creativo sobre la vida como podría ser. Como un espejo de lo que hace falta para alcanzar la hipercreatividad humana. Cómo podremos aumentar la producción de novedades, será el camino para acercarnos a dicho modelo.

Pensamos que los mundos bioinmersivos producen un entorno que desafía la creatividad humana. También permite comparar y reflexionar sobre los modelos creativos basados en vida artificial. La relación entre la creatividad humana y la biología sintética podría llevarnos a un nivel más alto de innovaciones y podría acelerar la producción cualitativa de nuevas formas de adaptación.

François Jacob (1981) en su propuesta del Juego de los Posibles, explica cómo funciona la evolución. Pero no es un modelo. Habla de la imposibilidad por ahora del modelo, pues no se conocen las maneras como se producen estas decisiones de selección, más allá de lo aleatorio, en una actividad de bricolaje, donde la vida toma lo que tiene a mano, se sirve y se despliega en un continuum de vida a través de irrupciones y producción de novedades. 
De esta forma Jacob explica cómo emerge la adaptación, como lo actual de una posibilidad.

Al principio tenemos posibilidades, luego éstas se vuelven reales. En este sentido, la evolución es un asunto de posibilidades. La relación de ello con los mundos posibles arroja luces acerca de cómo éstos generan actualizaciones de posibilidades, más que descripciones de un estado de un mundo predefinido e intencional en una dirección.

Deseamos encontrar la categoría de pensar lo imposible en la evolución de la vida. La encontramos en la idea de cómo incrementar las novedades en la creatividad y en la evolución de sistemas sintéticos. En este sentido, seleccionamos el bioarte inmersivo por su capacidad para localizar un mundo posible, y simultáneamente para producir un mundo desconocido con sus propias reglas o patrones. Y sin embargo y a pesar de ello, de no mimetizar el mundo conocido, ni de ser parte de él. En los entornos de lo virtual esto es completamente posible y a la vez deja espacios abiertos, indeterminados, esperando nuevas opciones que no han sido simuladas. Pero puede tratarse de la experiencia a través de la sensibilidad humana; ella participa contribuyendo con interacciones, pero no define su contenido o alcance. Con la interacción entre los agentes de todos los sistemas vivos, sociales y artificiales que intervienen, nuevos niveles de creatividad pueden ser alcanzados. Se trata de un proceso de abajo hacia arriba, que se despliega entre los interactores humanos y no humanos. ¿Entre los organismos vivos y semi-vivos, cuáles serían las maneras particulares de afectación con la interacción? Tal vez si pudiéramos precisar el modelo de los tipos de interacciones que se producen en relación con las distintas clases de agentes que intervienen, obtendríamos una clave acerca de cómo generar autoproducción del modelo deseado de creatividad, basado en la evolución abierta. Podemos alcanzar lo imposible a través de encontrar el camino para un nivel de creación más alto en los modelos y en los agentes que participan en mundos inmersivos de vida artificial.

\section{BIBLIOGRAFÍA}

BEATTY, J. (2011) Replaying Life's Tape. University of British Columbia.

BEDAU, M.A. (2004) Artificial Life illuminates human hyper-creativity en Dimitry B. (ed.) Biomediale: Contemporary Science and Genomic Culture. Kalingrad: The National Center for Contemporary Arts, pp 216-231.

BEDAU, M.A. (2006). “The evolution of complexity” en el Simposio: “The making up of organisms: mapping the future of biological models and theories". Ecole Normale Supérieure, Paris.

BEDAU, M.A., McCaskill, J.S., Packard, N.H., Rasmussen, S. (2010) Living Technology: Exploiting Life's Principles in Technology. Artificial Life 16. MIT Press, pp 89-97.

BEDAU, M.A. (2011) A functional account of degrees of minimal chemical life. Synthese, Springer.

CASTI, J. (1997). Would-be Worlds. How simulation is changing the frontiers of science. John Nueva York: Wiley and Sons. 
CATTS, O. Y ZURR, I. (2006). “Towards a new class of being. The Extended Body”. In: Organicities: Artnodes: Intersections between arts, sciences and technologies. Volume 6, November, pp: 1-9. www.uoc.edu/artnodes/6/dt/eng/catts_zurr.pdf.

CATTS, O. Y ZURR, I. (2011) Partial Life. Perth: Open Humanities press. SymbioticA, School of Anatomy and Human Biology - University of Western Australia.

CLARK, A. (1998) Being There: Putting Brain, Body and World Together Again. Nueva York: Bradford.

DAWKINS R. (1982). The Extended Phenotype: The Gene as the Unit of Selection. Oxford: W. H. Freeman and Company.

DAWKINS, R. (2006). The Selfish Gene. New York: Oxford University Press.

FONTANA, W. BUSS, L.W. (2011) "What would be conserved if "the tape were played twice? Santa Fe Institut y Yale University, New Haven.

GOULD, S.J. (1989). Wonderful Life: The Burges Shale and the Nature of History. New York: Norton. GOULD, S. J. (1995). La sonrisa del flamenco: reflexiones sobre historia natural. Madrid: Critica.

HERNÁNDEZ, I. (2002) Mundos virtuales habitados: espacios electrónicos interactivos. Colección estética contemporánea. Bogotá: Pontificia Universidad Javeriana.

HERNÁNDEZ, I., (2010). “Estética de lo posible: vidas que emergen y vidas preexistentes”. En: Hernández, I., Niño, R. (editores académicos). Estética, vida artificial y biopolítica: expansiones en la evolución cultural y biológica a través de la tecnología. Colección Estética contemporánea, Bogotá: Pontificia Universidad Javeriana.

HERNÁNDEZ, I., NIÑO, R., HERNÁNDEZ-GARCIA J. (2013). “Estética, sistemas complejos adaptativos y ciudad" En Estética y sistemas abiertos: procesos de no-equilbrio entre el arte, la ciencia y la ciudad. (Hernández, I., Niño, R.) Colección Estética contemporánea, Bogotá: Pontificia Universidad Javeriana.

HERNÁNDEZ, I. (2016) Mundos bioinmersivos: la creatividad en evolución. Colección estética contemporánea, Bogotá: Pontificia Universidad Javeriana.

HERNÁNDEZ, I. (ed.) (2016) Estética de los mundos posibles: inmersión en la vida artificial, las artes y las prácgticas urbanas. Colección Estética contemporánea, Bogotá: Pontificia Universidad Javeriana.

HUNEMAN, P. (2008a). "Emergence and Adaptation" in Minds and Machines, 18, pp. 493-520. Springer.

HUNEMAN, P. (2008b) “¿Emergence made Ontological? Computational versus Combinatorial Approaches". Journal of Philosophy of Science, No. 38, pp. 21-57

HUNEMAN, P. (2012a) "Determinism, predictability and open-ended evolution: lessons from computational emergence", Synthese, 185, pp. 195-214. Springer Science + Business Media B.V. IHPST.

HUNEMAN, P. (2012b) Special Sciences and the Unity of Science. Springer Science + Business Media B.V. IHPST.

JACOB, F. (1981). Le jeu des possibles: Essai sur la diversité du vivant. Paris: Fayard.

KAUFFMAN, S. (1995) At home in the univers: the search for the laws of self. Organization and complexity . Oxford.

PRIGOGINE, I. STENGERS, I. (1997). La nueva alianza: metamorphosis de la ciencia. Madrid: Alianza. ROSNAY, J. DE (1995). El hombre simbiótico. Madrid: Cátedra. 


\section{Páginas web:}

Eduardo Kac: www.ekac.org

Thomas Ray: http://urml.arc.org/tierra

Jon McCormack: http://jonmccormack.info/ jonmc/sa/

Oron Catts e Ionat Zurr / The Tissue Culture and Art Project: http://www.symbiotica.uwa.edu.co

José Wagner García: http://dialogosarteciencia.blogspot.com.co/2013/05/arte-e-ciencia-nacontemporaneidade.html

\section{NOTAS}

1. www.ekac.org

2. http://jonmccormack.info/ jonmc/sa/

\section{RESÚMENES}

Este artículo se propone argumentar acerca de las mutaciones ontológicas que están sobreviniendo en el horizonte contemporáneo de las artes biomediales y electrónicas, a propósito de las transformaciones que producen las epistemologías biocomputacionales no humanas en intersección con el biarte inmersivo. Estas se producen en la biología sintética, en la generación de vida química mínima no orgánica en laboratorio y en la realización de bioarte sintético con tecnologías vivas.

L'article propose une discussion à propos des mutations ontologiques propres à l'art biomédial et électronique. En ce qui concerne spécifiquement les changements produits par les épistémologies biocomputationelles non humaines. Elles donnent lieu á une relation avec le bioart immersif. Ceux-ci sont produits par la biologie de synthèse, à travers la génération de vie chimique non organique dans le laboratoire et dans la réalisation du bioart synthétique en utilisant des technologies vivantes.

\section{ÍNDICE}

Palabras claves: mundos bioinmersivos, artes biomediales y electrónicas, biología sintética, vida artificial, tecnologías vivas

Mots-clés: mondes bioinmersives, arts biomediales et éléctroniques, biologie de synthése, vie artificielle, technologies vivantes 


\section{AUTOR}

\section{ILIANA HERNÁNDEZ-GARCÍA}

Ph.D. en Estética de la Universidad de la Sorbona, Paris-I. Posdoctorado Senior en Filosofía de la Ciencia de l'Ecole Normale Supérieure / Institut d'Histoire et Philosophie des Sciences et Techniques, Universidad de la Sorbona, Paris-I, investigadora invitada de la Maison des Sciences de l'Homme. Profesora Titular del departamento de Estética de la Facultad de Arquitectura y Diseño de la Pontificia Universidad Javeriana, donde es Directora del grupo de investigación en Estética, nuevas tecnologías y habitabilidad. Es Directora de la Colección en Estética contemporánea y Profesora del Doctorado en Ciencias Sociales y Humanas. Es investigadora en estética de las artes electrónicas y biomediales et la vida artificial y los mundos virtuales inmersivos. ilianah@javeriana.edu.co 